\title{
Effect of Short-Term Tacrolimus Exposure on Rat Liver: An Insight into Serum Antioxidant Status, Liver Lipid Peroxidation, and Inflammation
}

\author{
N. Fatima $\mathbb{D}^{1},{ }^{1,2}$ N. Sheikh $\mathbb{D},{ }^{1}$ A. R. Satoskar $\left(\mathbb{D},{ }^{2}\right.$ T. Akhtar $\mathbb{D}^{3},{ }^{3}$ A. Tayyeb $\mathbb{D},{ }^{4}$ I. Ashfaq $\mathbb{D},{ }^{1}$ \\ N. Ryan $\mathbb{D}^{2},{ }^{2}$ S. Ambreen $\mathbb{D}^{1,5}$ B. K. Jha $\mathbb{D}^{2},{ }^{2}$ and S. Oghumu $\mathbb{D}^{2}$ \\ ${ }^{1}$ Cell and Molecular Biology Lab, Institute of Zoology, University of the Punjab, Q-A Campus, Lahore 54590, Pakistan \\ ${ }^{2}$ Department of Pathology and Microbiology, Wexner Medical Center, The Ohio State University, Columbus, OH 43210, USA \\ ${ }^{3}$ Department of Pharmacology, University of Health Sciences, Lahore 54600, Pakistan \\ ${ }^{4}$ School of Biological Sciences, University of the Punjab, Q-A Campus, Lahore 54590, Pakistan \\ ${ }^{5}$ Institute of Laboratory Medicine, Clinical Chemistry and Molecular Diagnostics, University of Leipzig, Germany
}

Correspondence should be addressed to N. Sheikh; s_nadeem77@yahoo.com

Received 24 December 2020; Revised 8 February 2021; Accepted 11 February 2021; Published 24 February 2021

Academic Editor: Agnieszka Dobrzyn

Copyright @ 2021 N. Fatima et al. This is an open access article distributed under the Creative Commons Attribution License, which permits unrestricted use, distribution, and reproduction in any medium, provided the original work is properly cited.

Tacrolimus (TAC) is an immunosuppressive drug, optimally used for liver, kidney, and heart transplant to avoid immune rejection. In retrospect, a multitude of studies have reported effects of TAC, such as nephrotoxicity, diabetes, and other complications. However, limited information is available regarding short-term exposure of TAC on the liver. Therefore, the present study was designed to unravel the effects of short-term exposure of TAC on a rat model. The animal model was established by TAC administration for $6,12,24$, and $48 \mathrm{~h}$ time points. Liver histopathological changes were observed with PAS-D, reticulin stain, and immunostaining of PCNA and CK-7 coupled with glycogen quantification in a liver homogenate. TUNEL assay was performed to evaluate the DNA damage in the liver. Concentration of GSH and activities of SOD and CAT in the serum were measured to assess the antioxidant status, whereas liver tissue MDA level was measured as a biomarker of oxidative stress. Hepatic gene expression analysis of IL-10, IL-13, SOCS-2, and SOCS-3 was performed by RT-PCR. Results revealed marked changes in liver architecture of all TAC-treated groups, as evidenced by sinusoid dilation, hepatocyte derangement, glycogen deposition, and collapsed reticulin fibers. Significant increase in PCNA and CK-7 immunostaining along with the presence of TUNEL-positive cells was revealed in treatment groups as compared to the control group. Serum antioxidant enzyme status was markedly decreased, whereas the liver MDA level was increased in TAC treatment groups indicating oxidative stress induction. The gene expression profile of cytokines was significantly upregulated in treatment groups highlighting an inflammatory response. In conclusion, results of the current study propose that even a short-term TAC exposure can induce change in antioxidant status and lipid peroxidation. Therefore, these factors should be considered to avoid and minimize immunosuppression-related issues in a prolonged course of treatment.

\section{Introduction}

Tacrolimus (TAC) is one of the widely used immunosuppressive drugs (ISD) for the prophylaxis of transplant patients [1]. TAC belongs to the category of calcineurin inhibitor (CNI); these drugs work by inhibiting calciumdependent events and are being used for liver transplantation since 1998 [2, 3]. Although use of TAC has markedly reduced the risk of rejection, adverse effects of immunosuppressive drugs are still a major concern [4]. TAC works by binding to an immunophilin FK506 binding protein (FKBP) and after complex formation, inhibits calcium-dependent events, as a result $\mathrm{T}$ cell proliferation is inhibited which impairs $\mathrm{T}$ cellmediated cytotoxicity. Furthermore, B cell growth and antibody production is also affected due to suppression of $\mathrm{T}$ cell-derived growth factors, and antigen presentation is 
spared [5]. Myriads of adverse effects and contraindications of TAC have been recently reported in transplant patients which include hepatotoxicity, encephalopathy, diabetes mellitus, nephropathy, increased susceptibility to COVID-19, and other infectious diseases, owing to immunosuppression [6-10]. Previous studies have reported nephrotoxicity in patients receiving TAC as immunosuppressive therapy after liver transplant. TAC-induced renal and pulmonary toxicity has been reported with morphopathological alterations and cellular necrosis $[11,12]$. Previous studies have also reported development of hepatic infarction in post liver transplant patients, as an effect of TAC [13]. Immunosuppressive drugs have some off target effects which may lead to production of reactive oxygen species (ROS) and induction of apoptotic cell death due to impaired mitochondrial and $\mathrm{T}$ cell functions [14]. Therefore, liver-targeted management should be taken into account to avoid liver complications $[15,16]$.

Association of TAC and change in oxidative stress marker 8,12-iso-isoprostane F-2alpha-VI has been described previously in heart transplant patients [17]. Oxidative stress and mitochondrial dysfunction has also been reported in an in vitro organoid model of nephrotoxicity in TAC-induced renal injury characterized by oxidative stress and production of inflammatory cytokines $[9,18]$. Furthermore, DNA damage and expression of proliferating cell nuclear antigen (PCNA) and cytokeratin 7 (CK-7) are important biomarkers to assess liver injury. PCNA and CK-7 immunohistochemistry and gene expression analysis have shown increased expression in hepatotoxicity [19-22]. Likewise, the cytokine profile is altered following liver injury. Proinflammatory cytokines, interleukin- (IL-) 10, and IL-13 exhibit an increased expression in rat liver injury to protect the tissue from damage [23]. A role of IL-10 has been previously described owing to progression of liver inflammation and oxidative stress-related liver injury. An upregulated expression of IL-10 and decreased activity of superoxide dismutase (SOD) with increased malondialdehyde (MDA) level has been reported due to cyclophosphamideinduced immunosuppression in rats [24]. These cytokines trigger activation of suppressor of cytokine signaling (SOCS) genes, which in turn can activate other signal transduction pathways, such as the JACK/STAT pathway, to promote cell proliferation and apoptosis [25].

Paucity of information regarding the oxidative effects of TAC on rat liver demanded a study to be designed with an aim to assess liver histopathological changes, DNA damage, expression of PCNA and CK-7, serum antioxidant status, lipid peroxidation level in the liver, and change in hepatic gene expression pattern of cytokines due to short-term exposure of TAC on rat.

\section{Materials and Methods}

2.1. Experimental Design. Male Wistar rats $(250 \pm 25 \mathrm{~g})$ of 10 weeks old (sexually mature) were raised and caged in the animal house of the Institute of Zoology, University of the Punjab, Lahore, Pakistan, after ethical committee approval (D/622/U.Z) and fed with normal rat chow and water ad libitum. After being acclimatized, rats were randomly divided into 4 experimental groups and one control group, having 9 animals in each group $(n=9)$. An oral dose of $3 \mathrm{mg} / \mathrm{kg}$ of TAC (Sigma, Cat. No. Y0001926) was administered once, for $6,12,24$, and $48 \mathrm{~h}$, as described previously [26]. The rats were sacrificed after the aforementioned time points with blood sample and liver tissue collection.

2.2. Histopathological Analysis. For histological analysis, a portion from the left lobe of the liver tissue was used, followed by fixation in formalin and embedding in paraffin for histological analysis. Paraffin-embedded tissue sections were cut $6 \mu \mathrm{m}$ thick, and slides with tissue sections were incubated overnight at $37^{\circ} \mathrm{C}$. PAS-D, reticulin, immunostaining of PCNA and CK7 , and terminal deoxynucleotidyl transferase dUTP nick end labeling (TUNEL) staining were performed as a preliminary finding to detect liver injury.

2.3. PAS-D Staining. Formalin-fixed and paraffin-embedded (FFPE) tissue slides were subjected to PAS-D staining using a kit (Sigma-Aldrich Periodic Acid-Schiff (PAS) Staining System 395) according to the manufacturer's protocol, as described previously [27].

2.4. Reticulin Staining. Reticulin staining was performed using a Reticulum Stain kit (Sigma-Aldrich, HT102) according to the manufacturer's protocol. Briefly, tissues were deparaffinized, hydrated, and oxidized in potassium permanganate solution with a quick rinse in tap water. Slides were subjected to bleaching agent, oxalic acid followed by iron alum-treated sensitization for effective impregnation of silver. Sensitized slides were further exposed to an ammoniacal solution of silver nitrate solution. Reduction of tissue sections was carried out with aqueous formalin and toned with gold chloride solution, followed by removal of unreduced silver with sodium thiosulphate solution. Sections were then dehydrated, cleared, mounted, and observed using a light microscope.

2.5. Immunohistochemical Analysis. Immunohistochemistry was performed to identify the presence and extent of PCNA and CK-7 expression in liver tissue. Tissue sections were deparaffinized in xylene and rehydrated to water through graded ethanol. Heat-induced epitope retrieval was performed, and sections were washed by immersion in PBS. After washing, sections were blocked followed by another wash in PBS, and samples were incubated with $10 \%$ normal goat serum (Vector Laboratories S-1000) in a humidified chamber for 30 minutes, followed by incubation with primary antibody solution (PCNA MAB424, Millipore Sigma, USA, CK-7 RCK105) in $10 \%$ normal goat serum. Concentration of primary antibodies used was $1: 100$, and slides were incubated overnight at $4^{\circ} \mathrm{C}$ in a humidified chamber. After flicking off the primary antibody, slides were washed in PBS and incubated with biotinylated secondary antibody for 30 minutes (Vector Laboratories BP-9200) at room temperature (RT) in a humidified chamber. Tissue section without a primary antibody was kept as a negative control to check the background staining of liver tissue. After washing with PBS, slides were incubated with Streptavidin-HRP (SA-5004 Vector Laboratories) for 30 minutes at RT in a humidified chamber, followed by another PBS wash. Slides were finally incubated with DAB solution 
(Vector DAB substrate SK-4100) and washed with $\mathrm{dH}_{2} \mathrm{O}$. Slides were further counterstained with Hematoxylin 2 (Fisher Scientific), dehydrated through graded ethanol to xylenes, mounted, and observed under a light microscope.

2.6. Assessment of DNA Damage by TUNEL Assay. DNA damage in all experimental groups was analysed using TUNEL assay (ab66108) according to the instructions provided, as described previously [27]. Three stained slides were observed, and the image was captured using a fluorescent microscope to observe the TUNEL-positive cells, and ImageJ software was used to count the cells.

2.7. Glycogen in Liver Tissue Homogenate. Liver tissue homogenate was used to determine the concentration of glycogen to further confirm the deposition of glycogen in liver tissue, as described previously [28].

\subsection{Serum Antioxidants}

2.8.1. Glutathione Concentration. Serum glutathione (GSH) concentration was measured using a glutathione colorimetric detection kit (Invitrogen EIAGSHC). Briefly, serum was treated with $5 \%$ SSA and incubated for 10 minutes at $4^{\circ} \mathrm{C}$ followed by centrifugation at $14,000 \mathrm{rpm}$ for 10 minutes at $4^{\circ} \mathrm{C}$. The supernatant was collected and added in a 96 -well plate followed by dilution with an assay buffer. Absorbance was read at $405 \mathrm{~nm}$ in a microplate reader.

2.8.2. Superoxide Dismutase Activity. Serum samples were used to measure the activity of SOD using a SOD assay kitWST (Sigma 19160), according to the manufacturer's instructions. Briefly, serum sample, $\mathrm{dH}_{2} \mathrm{O}$, and WST working solution and enzyme working solution dilution buffer were added in a 96-well microplate, and the plate was incubated at $37^{\circ} \mathrm{C}$ for 20 minutes. Absorbance at $450 \mathrm{~nm}$ was read in a microplate reader.

2.8.3. Catalase Activity. Activity of catalase (CAT) in serum samples was measured by a catalase activity colorimetric assay kit (ab83464) according to the manufacturer's instructions. Briefly, serum samples in a 96-well plate were treated with hydrogen peroxide and incubated for 30 minutes followed by addition of stop solution and development solution. Absorbance was read at $570 \mathrm{~nm}$ in a microplate reader.

\subsection{Lipid Peroxidation Assay in the Liver}

2.9.1. MDA Level. Liver tissue homogenate was used to assess lipid peroxidation by measuring the level of MDA using the calorimetric assay kit (MAK085) according to the manufacturer's instructions. Briefly, tissue was lysed in MDA lysis buffer and proteins were precipitated. A sample was taken in a 96-well plate and treated with thiobarbituric acid, incubated at $95^{\circ} \mathrm{C}$ for 60 minutes followed by cooling at room temperature for 10 minutes. Absorbance was read at $532 \mathrm{~nm}$ in a microplate reader.

2.10. Gene Expression Analysis with Real-Time PCR (RT-PCR). Expression profile of cytokines was determined by RT-PCR analysis. Freshly excised liver tissues were used for RNA extrac- tion using the TRIzol method. After measuring the concentration of RNA with NanoDrop, cDNA was synthesized using a cDNA synthesis kit (Thermo Scientific) according to the manufacturer's protocol. Gene expression level of IL-10 (forward: TGTGAAAATAAGAGCAAGGCAGTG, reverse: CATTCA TGGCCTTGTAGACACC), IL-13 (forward: CAGCATGGT ATGGAGTGTGG, reverse: TGGGCTACTTCGATTTTGGT), SOCS-2 (forward: TCAGCTGGACCGACTAACCT, reverse: TGTCCGTTTATCCTTGCACA), and SOCS-3 (forward: AGCTCCAAAAGCGAGTACCA, reverse: TGACGCTCAAC GTGAAGAAG) was investigated by a PikoReal ${ }^{\mathrm{TM}}$ Real-Time PCR system using a SYBR-GREEN master mix. Ct value was measured by an amplification curve, and results were normalized using GAPDH (forward: GAAACCTGCCAAGTATGA, reverse: GCTGTAGCCGTATTCATT) as an endogenous control.

2.11. Statistical Analysis. Statistical analysis was performed by one-way ANOVA, and data was normalized by Tukey's post hoc test using GraphPad Prism 5 (San Diego, CA). Results are presented as mean \pm SEM, and $P>0.05$ was considered as statistically significant.

\section{Results}

3.1. Short-Term Tacrolimus Exposure Induces Acute Liver Injury. Histopathological alterations from three fields, selected randomly, were analyzed by an independent pathologist to assess changes in liver architecture in all TAC-treated groups. PAS-D staining indicated intact liver architecture in the control but dilation of liver sinusoids; deranged hepatocyte with cytoplasmic swelling was evident as described previously [27] in all treatment groups. Furthermore, the presence of glycogen globules highlighted liver injury in all treatment groups (Figure 1(a)). The glycogen deposition was also confirmed in liver tissue homogenate.

Reticulin-stained slide section of the control group showed intact liver architecture with normal reticulin fibers, while treatment groups indicated loss of liver architecture due to collapse of reticulin fibers (Figure 1(b)). Condensed reticulin fibers appearing as grayish black fibers signal loss of underlying parenchyma and damage of tissue as hallmark of liver injury. Reticulin fibers are part of the extracellular matrix and give a clue of disturbed architecture of hepatic plates and collapse of reticulin framework [29].

3.2. Tacrolimus Exposure Results in Liver Damage and Enhanced Staining of PCNA and CK-7. Three fields were selected randomly, and slides were analyzed and evaluated by an independent pathologist. Stained slide sections were scored by immunoreactivity scoring (IRS) method [30]. Intensity of staining and percentage of immunopositive cells were determined to evaluate IRS. Furthermore, every tissue sample was classified into IRS points (0-12) as no, mild, moderate, and strong staining. A higher degree of brown staining of cytoplasm and nucleus normally shows a higher level of liver tissue damage and steatosis. Significant differences of immune reaction to PCNA and CK-7 antibodies were observed between experimental and control groups as shown in Figures 1(c) 
Control

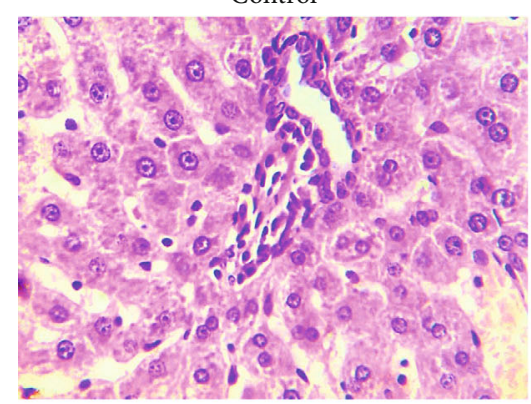

$6 \mathrm{~h}$

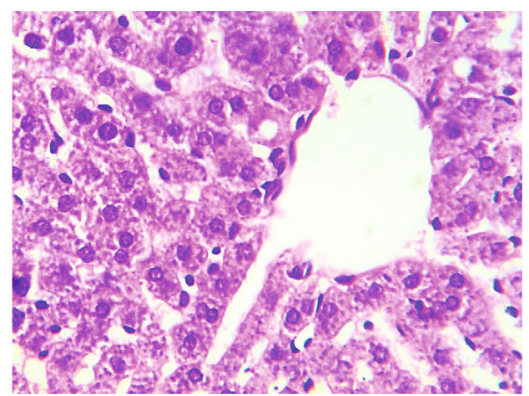

$12 \mathrm{~h}$

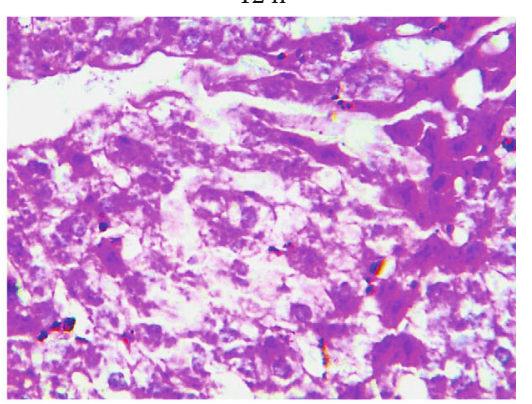

$48 \mathrm{~h}$

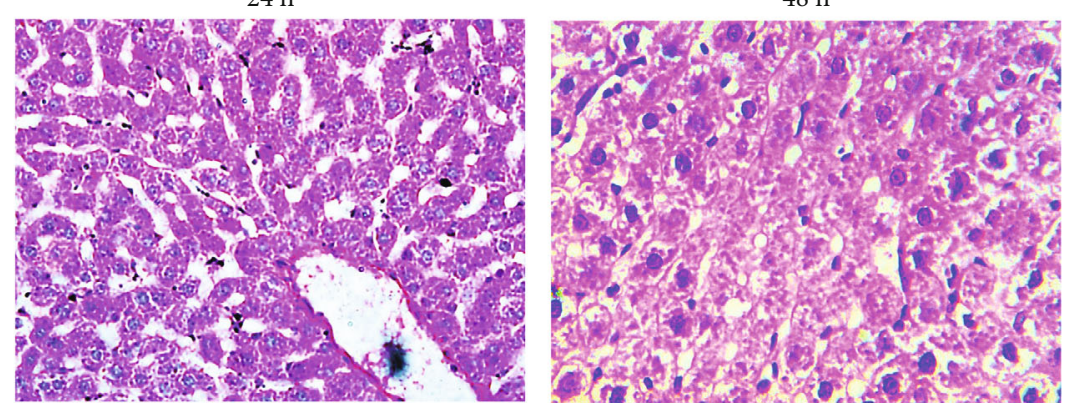

(a)
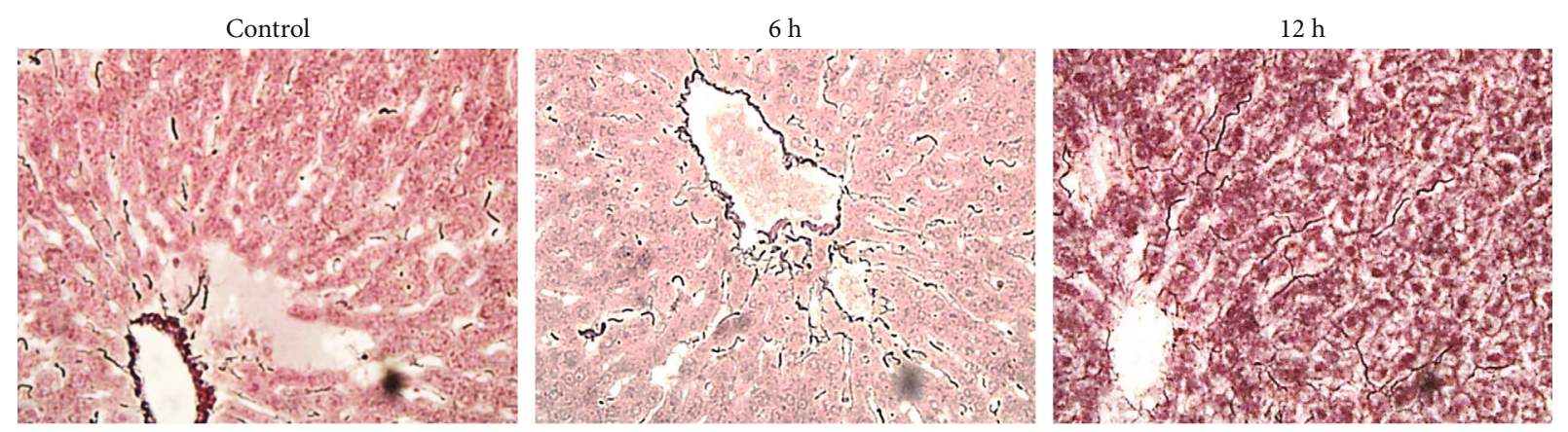

$24 \mathrm{~h}$

$48 \mathrm{~h}$
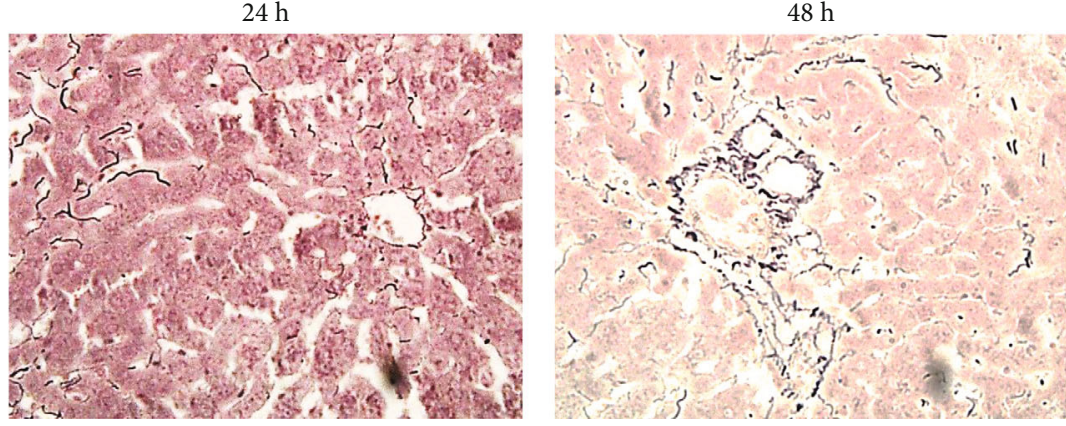

(b)

Figure 1: Continued. 
Control

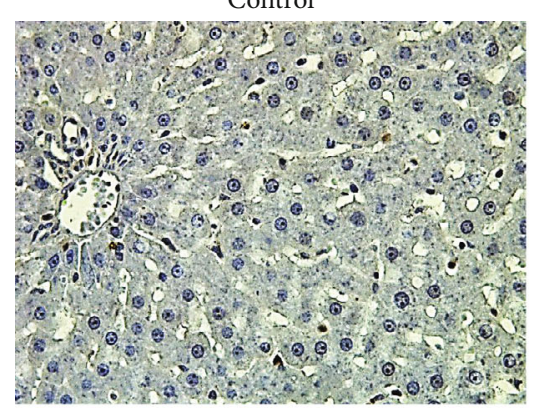

$6 \mathrm{~h}$

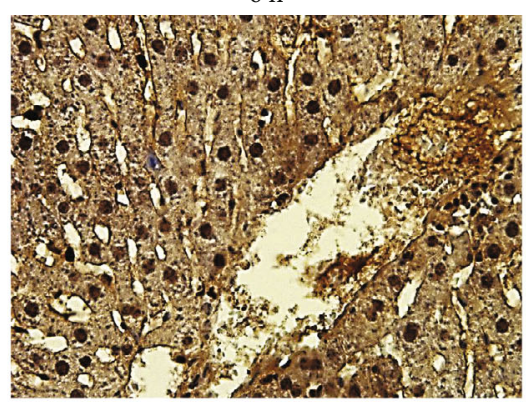

$12 \mathrm{~h}$

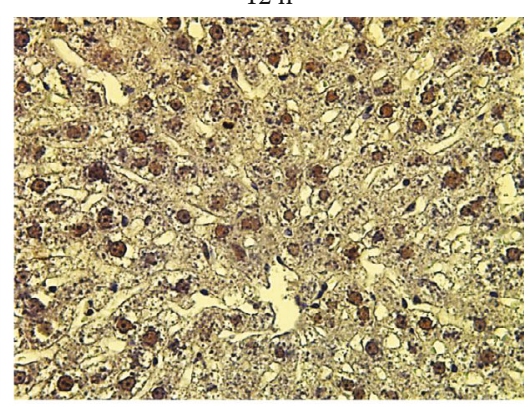

$24 \mathrm{~h}$

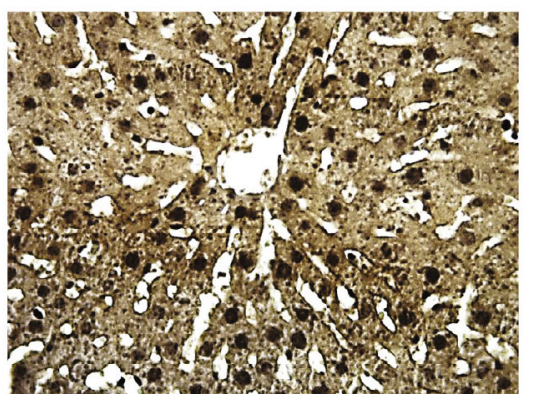

(c)

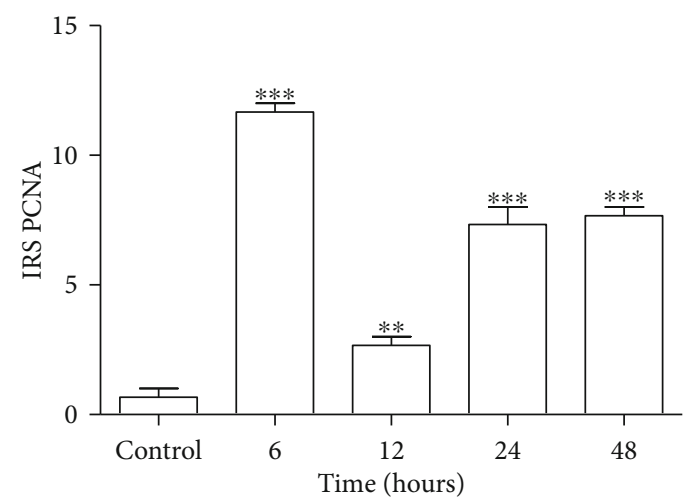

(d)

$48 \mathrm{~h}$

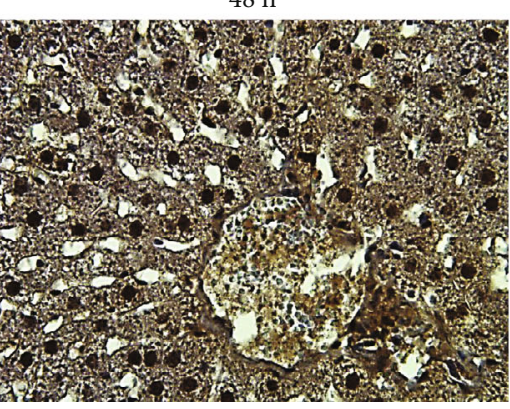


Control

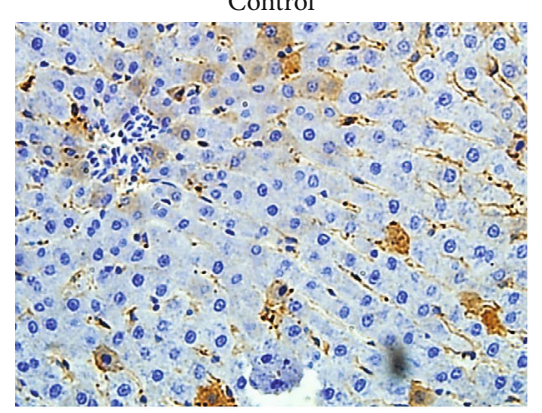

$6 \mathrm{~h}$

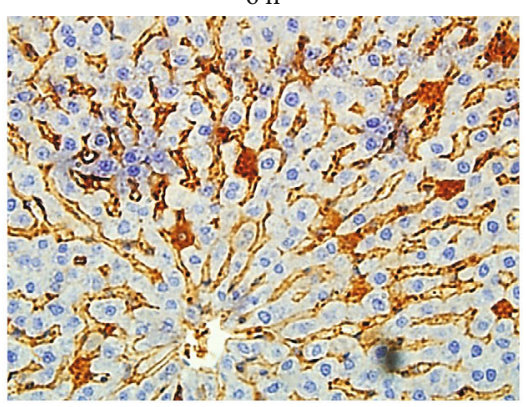

$12 \mathrm{~h}$

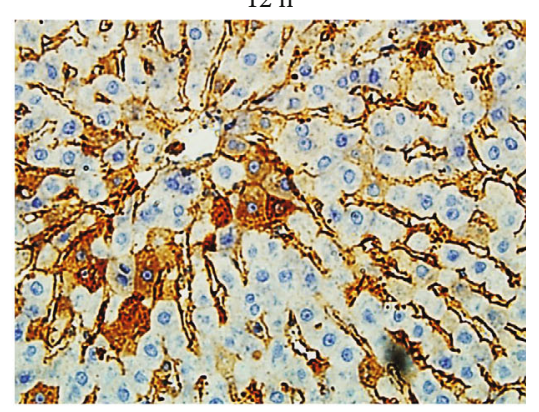

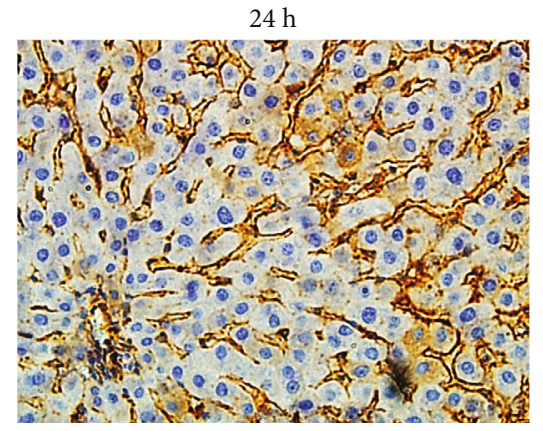

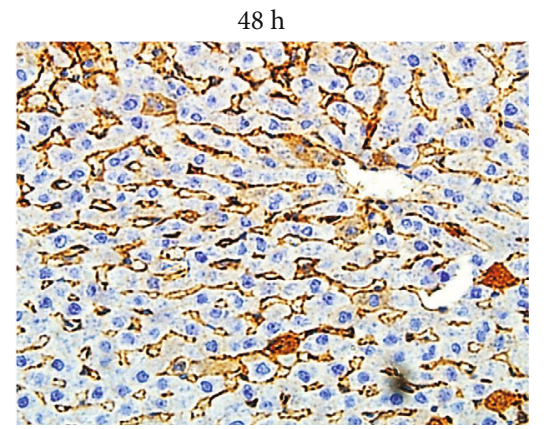

(e)

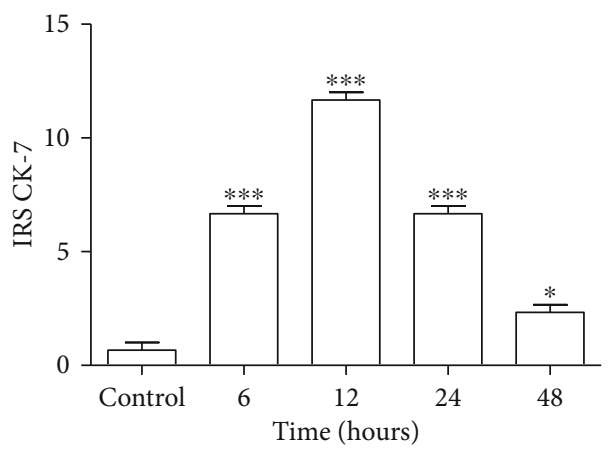

(f)

Figure 1: Continued. 

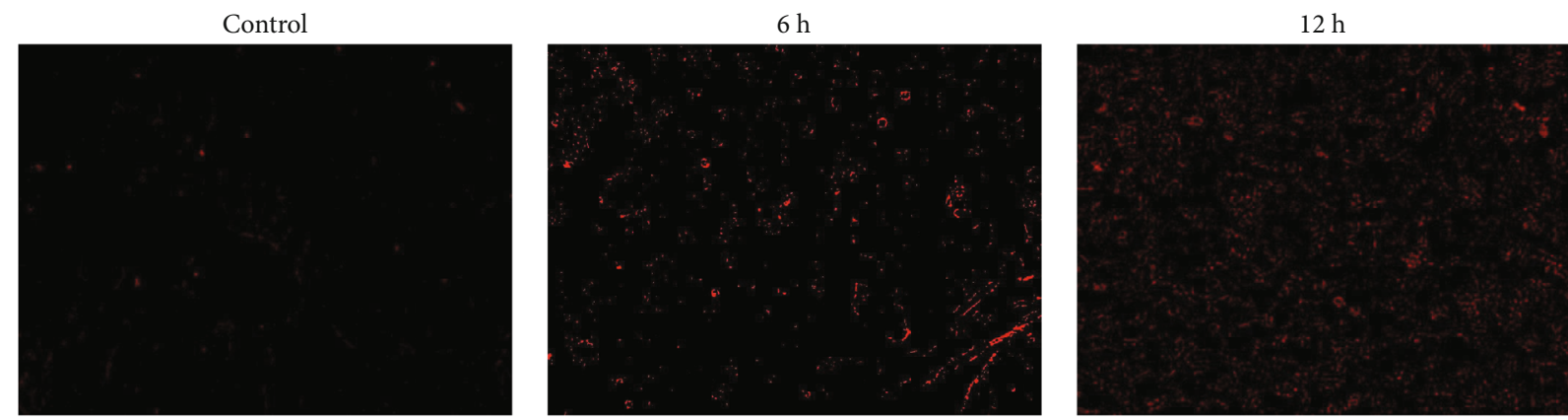

$24 \mathrm{~h}$

$48 \mathrm{~h}$
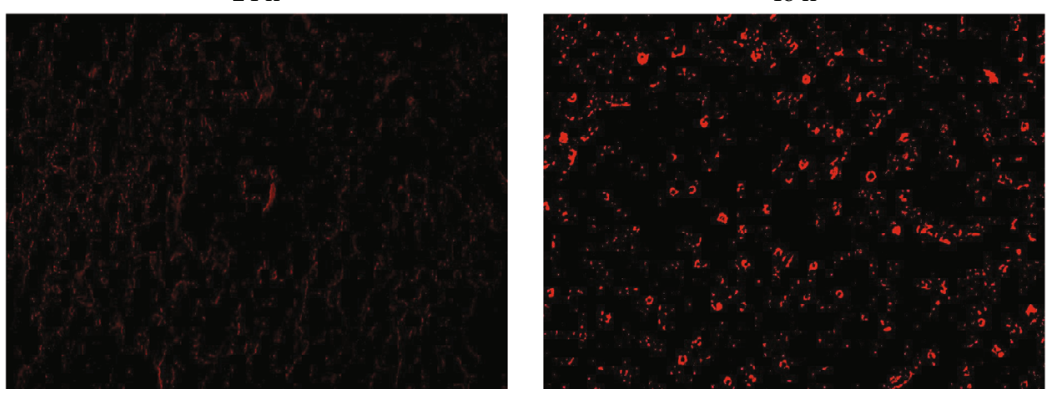

(g)

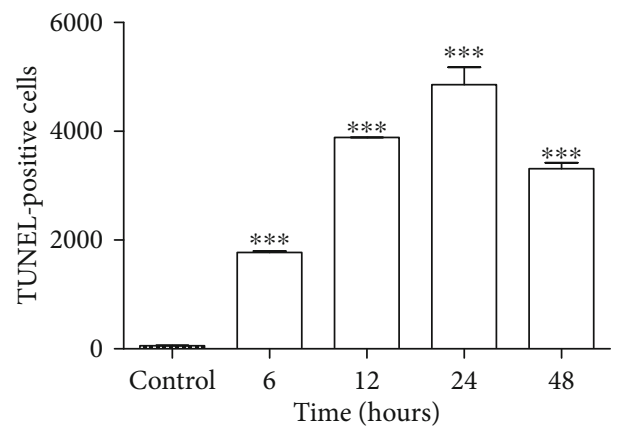

(h)

FIGURE 1: (a) Effect of short-term exposure of Tacrolimus on histopathological alterations in rat liver sections of control, 6, 12, 24, and 48 h treatment groups. PAS-D staining of liver control group showing intact liver architecture with almost no globules, while treatment groups indicate derangement of hepatocytes and presence of globules (arrows) due to collagen digestion (400x). Scale bar used is $50 \mu \mathrm{m}$. (b) Effect of short-term exposure of Tacrolimus on histopathological alterations in rat liver sections of control, 6, 12, 24, and 48 h treatment groups. Reticulin staining of control group showing intact liver architecture with normal reticulin fibers, while treatment groups indicate derangement of hepatocytes and collapsed reticulin network (black gray color) (400x). Scale bar used is $50 \mu \mathrm{m}$. (c) Effect of short-term exposure of Tacrolimus on PCNA immunostaining in rat liver tissue sections of control, 6, 12, 24, and $48 \mathrm{~h}$ treatment groups (400x). Scale bar used is $50 \mu \mathrm{m}$. Degree of brown staining shows intensity of immune reaction. (d) IRS of PCNA in all experimental groups was scored and data was analysed using one-way ANOVA. Data is represented as mean $\pm \operatorname{SEM}(n=3)$. ${ }^{*} P \leq 0.05,{ }^{* *} P \leq 0.01$, and ${ }^{* * *} P \leq 0.001$. (e) Effect of short-term exposure of Tacrolimus on CK-7 immunostaining in rat liver tissue sections of control, 6, 12, 24, and 48 h treatment groups (400x). Scale bar used is $50 \mu \mathrm{m}$. Degree of brown staining shows intensity of immune reaction. (f) IRS of CK-7 in all experimental groups was scored and data was analysed using one-way ANOVA. Data is represented as mean $\pm \operatorname{SEM}(n=3)$. ${ }^{*} P \leq 0.05,{ }^{* *} P \leq 0.01,{ }^{* * *} P$ $\leq 0.001$. (g) Effect of short-term exposure of Tacrolimus on DNA damage in rat liver sections of control, $6,12,24$, and $48 \mathrm{~h}$ treatment groups depicted by TUNEL assay staining (400x). Scale bar used is $50 \mu \mathrm{m}$. (h) TUNEL-positive cells in all experimental groups were counted using ImageJ, and data was analysed using one-way ANOVA. Data is represented as mean $\pm \operatorname{SEM}(n=3)$. ${ }^{*} P \leq 0.05$, ${ }^{* *} P \leq 0.01$, and ${ }^{* * *} P \leq 0.001$.

and 1(e), respectively. The tissue section used as a negative control did not show any background staining. As depicted by IRS, PCNA showed no immunoreactivity in control $(0.67 \pm 0.33)$ and strong immunoreactivity in the $6 \mathrm{~h}$ $(12 \pm 0.33)$, mild in the $12 \mathrm{~h}(2.7 \pm 0.33)$, and moderate in the $24 \mathrm{~h}(7.3 \pm 0.67)$ and $48 \mathrm{~h}(7.7 \pm 0.33)$ treatment groups (Figure 1(d)). Likewise, in the case of CK-7, no immunostain- ing was observed in the control group $(0.67 \pm 0.33)$, moderate immunoreactivity in the $6 \mathrm{~h}(6.7 \pm 0.33)$ and $24 \mathrm{~h}(6.7 \pm 0.33)$, strong in the $12 \mathrm{~h}(12 \pm 0.33)$, and mild in the $48 \mathrm{~h}(2.3 \pm 0.33)$ treatment groups (Figure 1(f)).

3.3. Short-Term Tacrolimus Exposure Results in DNA Damage. Results indicated DNA damage due to TAC 


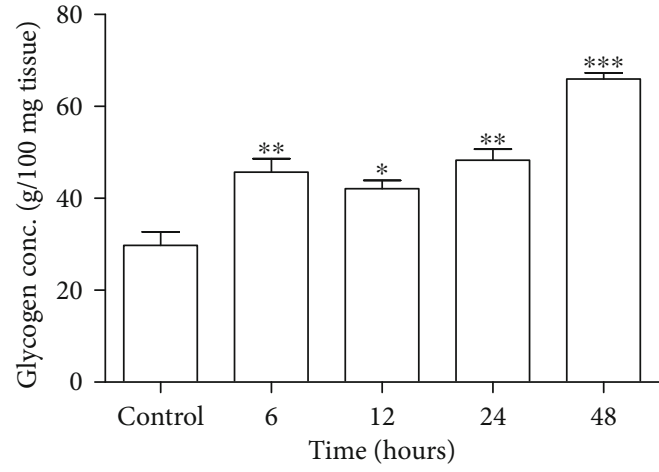

(a)

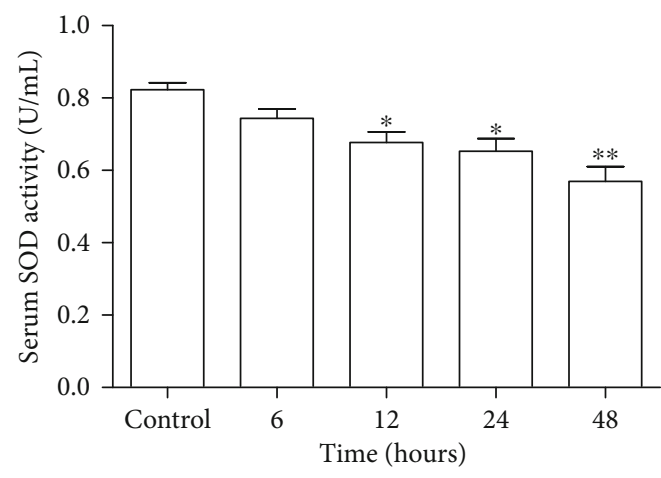

(c)

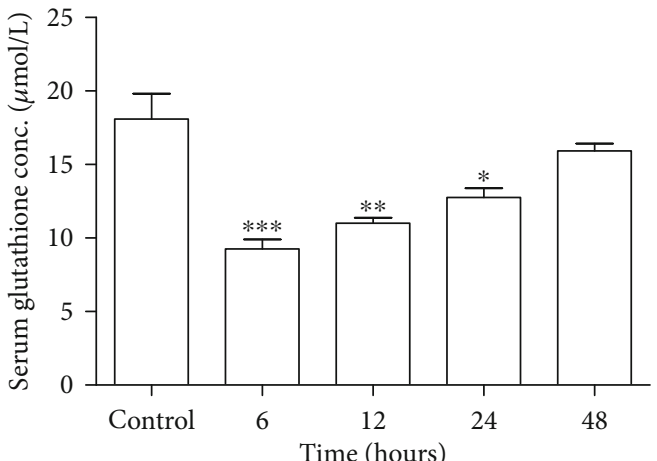

(b)

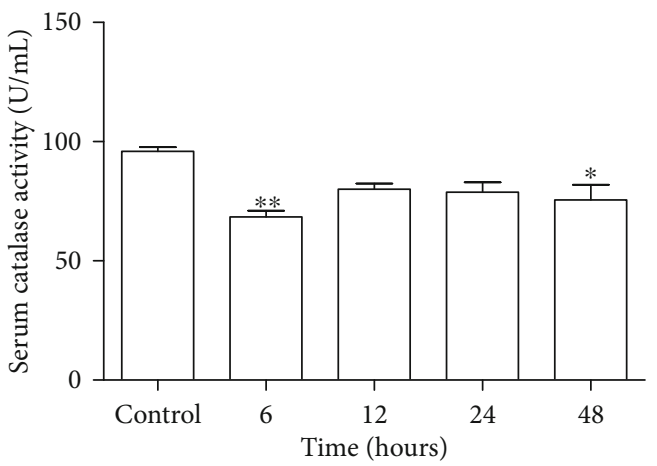

(d)

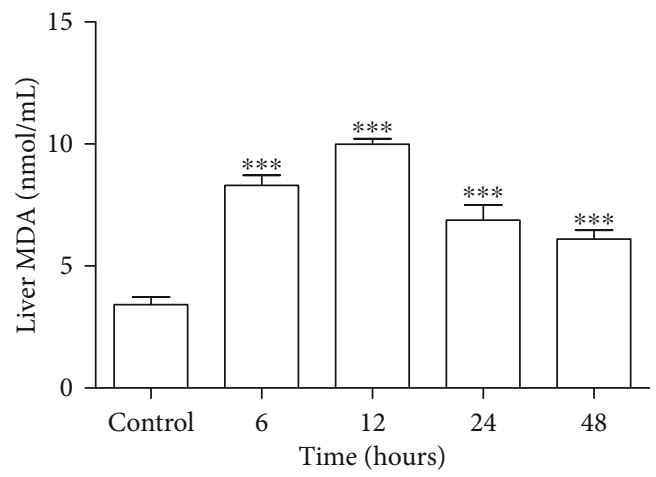

(e)

Figure 2: Effect of short-term Tacrolimus exposure on concentration of glycogen in liver tissue, serum antioxidants, and liver MDA level. (a) Increased glycogen in liver tissue homogenate is shown in graphical representation depicting the concentration measured in $\mathrm{g} / 100 \mathrm{mg}$ of tissue in control, 6-, 12-, 24-, and 48-hour treatment groups. Data is represented as mean \pm SEM $(n=6) .{ }^{*} P \leq 0.05,{ }^{* *} P \leq 0.01$, and ${ }^{* * *} P \leq$ 0.001. Serum antioxidant status and tissue MDA level are shown in graphical representation in control, 6-, 12-, 24-, and 48-hour treatment groups. (b) GSH concentration, (c) SOD activity, (d) CAT activity, and (e) MDA level. Data is represented as mean \pm SEM $(n=6) .{ }^{*} P \leq 0.05,{ }^{* *} P \leq 0.01$, and ${ }^{* * *} P \leq 0.001$.

exposure in all treatment groups (Figure 1(g)). Three fields were selected randomly, and TUNEL-positive cells were counted by ImageJ software. Data revealed significant DNA damage in $6(1772 \pm 22.9), 12$ (3885 \pm 2.65$), 24$ $(4857 \pm 323)$, and $48 \mathrm{~h}(3312 \pm 108)$ treatment groups as compared to the control group $(59.3 \pm 1.76)$. Maximum degree of DNA damage, however, was indicated by the $24 \mathrm{~h}$ treatment group (Figure $1(\mathrm{~h})$ ).

3.4. Increased Glycogen in Liver Tissue Homogenate due to TAC Exposure. Concentration of glycogen in liver tissue homogenate was increased in $6(46 \pm 2.9 \mathrm{~g} / 100 \mathrm{mg}), 12$ $(42 \pm 1.8 \mathrm{~g} / 100 \mathrm{mg}), \quad 24 \quad(48 \pm 2.4 \mathrm{~g} / 100 \mathrm{mg}), \quad$ and $48 \mathrm{~h}$ $(66 \pm 1.3 \mathrm{~g} / 100 \mathrm{mg})$ treatment groups as compared to the control group $(30 \pm 2.9 \mathrm{~g} / 100 \mathrm{mg})$ with maximum significant increase in the $48 \mathrm{~h}$ treatment group (Figure 2(a)).

\subsection{Decrease in Serum Antioxidants due to Short-Term Exposure of Tacrolimus}

3.5.1. Glutathione Concentration. Concentration of serum GSH indicated a decreasing trend in all treatment groups as 


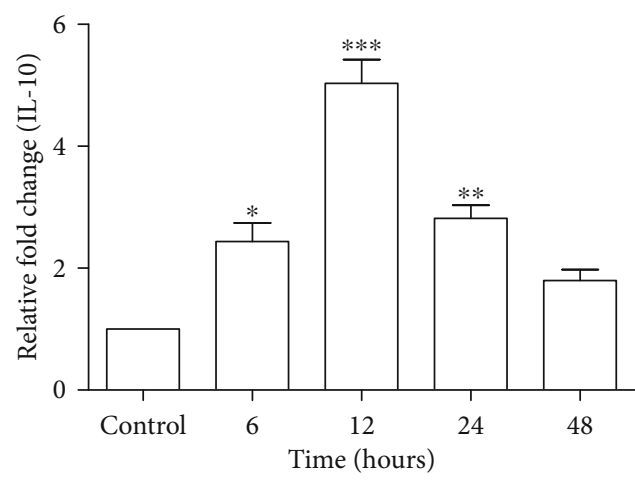

(a)

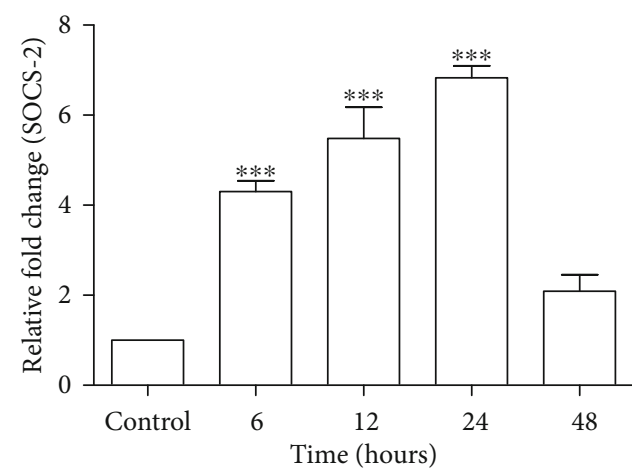

(c)

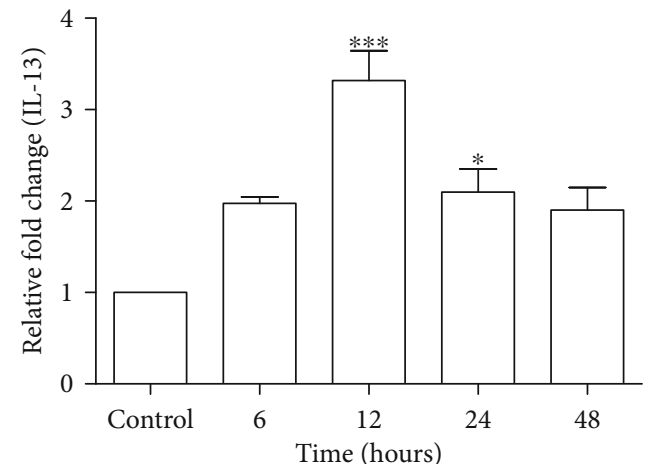

(b)

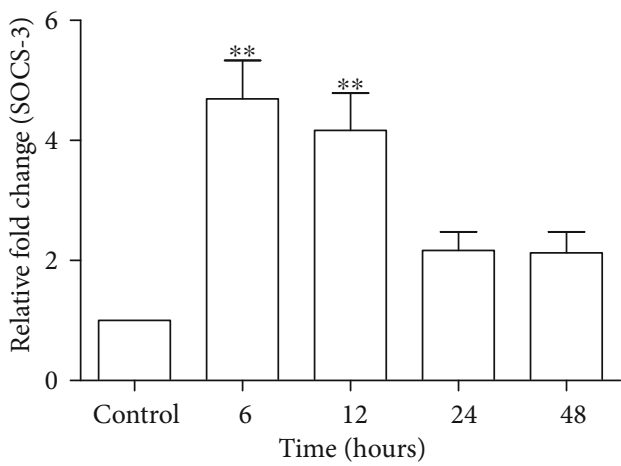

(d)

FIGURE 3: Effect of short-term Tacrolimus exposure on gene expression level of cytokines. RT-PCR results are shown in graphical representation depicting the relative fold change in control, 6-, 12-, 24-, and 48-hour treatment groups. (a) IL-10, (b) IL-13, (c) SOCS-2, and (d) SOCS-3. Data is represented as mean \pm SEM $(n=6)$ and normalized with the expression of a housekeeping gene, GAPDH. ${ }^{*} P \leq$ $0.05,{ }^{* *} P \leq 0.01$, and ${ }^{* * *} P \leq 0.001$.

compared to the control group (Figure 2(b)). However, significant decrease was observed in the $6(9.25 \pm 0.66 \mu \mathrm{mol} / \mathrm{L}), 12$ $(11.0 \pm 0.38 \mu \mathrm{mol} / \mathrm{L})$, and $24 \mathrm{~h}(12.75 \pm 0.62 \mu \mathrm{mol} / \mathrm{L})$ treatment group as compared to the control group $(18.08 \pm 1.74 \mu \mathrm{mol} / \mathrm{L})$ with no significant difference in the $48 \mathrm{~h}$ treatment group.

3.5.2. Superoxide Dismutase Activity. Activity of serum SOD revealed a decline in all treatment groups as compared to the control, with a significantly reduced activity in the 12 $(0.67 \pm 0.02 \mathrm{U} / \mathrm{mL}), \quad 24 \quad(0.65 \pm 0.03 \mathrm{U} / \mathrm{mL}), \quad$ and $48 \mathrm{~h}$ $(0.57 \pm 0.04 \mathrm{U} / \mathrm{mL})$ treatment groups as compared to the control group $(0.82 \pm 0.01 \mathrm{U} / \mathrm{mL})$ (Figure $2(\mathrm{c})$ ).

3.5.3. Catalase Activity. Activity of catalase in serum samples was decreased in all treatment groups as compared to the control group (Figure 2(d)). However, significant decline in the CAT activity was only observed in the 6 $(68 \pm 2.7 \mathrm{U} / \mathrm{mL})$ and $48 \mathrm{~h}(76 \pm 11 \mathrm{U} / \mathrm{mL})$ treatment groups as compared to the control group $(96 \pm 1.7 \mathrm{U} / \mathrm{mL})$.

3.6. Lipid Peroxidation Assessment in Liver Revealed Increased MDA Level due to Short-Term Exposure of Tacrolimus. Lipid peroxidation status showed a significant increase in all treatment groups as compared to the control group. A markedly increased level of MDA was observed in the $6(8.30 \pm 0.41 \mathrm{nmol} / \mathrm{mL}), 12(9.99 \pm 0.22 \mathrm{nmol} / \mathrm{mL}), 24$ $(6.88 \pm 0.62 \mathrm{nmol} / \mathrm{mL})$, and $48 \mathrm{~h}(6.11 \pm 0.35 \mathrm{nmol} / \mathrm{mL})$ treatment groups as compared to the control group $(3.42 \pm 0.31 \mathrm{nmol} / \mathrm{mL}$ ) (Figure 2(e)).

3.7. Tacrolimus Exposure Results in Upregulation of Cytokines. Gene expression analysis revealed an upregulation of IL-10, IL-13, SOCS-2, and SOCS-3 in experimental groups as compared to the control group as shown in Figure 3. IL-10 gene expression significantly increased in the $6(2.43 \pm 0.30$-fold $)$, 12 (5.03 \pm 0.39 -fold), and $24 \mathrm{~h}(2.81 \pm 0.21$-fold $)$ treatment groups as compared to the control group (1.00 \pm 0.00 -fold) (Figure 3(a)), whereas the IL-13 gene expression showed a significant upregulation in the $12(3.31 \pm 0.06$-fold $)$ and $24 \mathrm{~h}$ $(2.09 \pm 0.25$-fold $)$ treatment groups only, as compared to the control group $(1.00 \pm 0.00$-fold) (Figure $3(\mathrm{~b}))$. In the case of SOCS-2 and SOCS-3, the gene expression profile of SOCS-2 significantly increased in the $6 \mathrm{~h}(4.30 \pm 0.24$-fold $), 12 \mathrm{~h}$ $(5.48 \pm 0.69$-fold $)$, and $24 \mathrm{~h}(6.83 \pm 0.26$-fold $)$ treatment groups as compared to the control group (1.00 \pm 0.00 -fold) (Figure 3(c)). And the expression pattern of SOCS-3 significantly increased only in the $6 \mathrm{~h}(4.69 \pm 0.64$-fold $)$ and $12 \mathrm{~h}$ $(4.16 \pm 0.62$-fold) treatment groups as compared to the control group (1.00 \pm 0.00 -fold) (Figure $3(\mathrm{~d})$ ). 


\section{Discussion}

Although the use of immunosuppressive drugs has potentially lowered the risk of graft rejection, adverse effects in terms of prevalence of other diseases and life expectancy are still there [4]. Toxic effects of oral administration of TAC have also been described as liver inflammation coupled with activation of acute phase response (APR), with regulation of interferons and interleukins [26]. However, the short-term impact of TAC on oxidative stress has never been investigated. The current study was carried out to further explore the effects of short-term TAC exposure on antioxidant status and inflammation. The findings of this study revealed evident liver damage and glycogen deposition by significantly altering the liver architecture and change in antioxidant status of serum GSH and SOD, CAT, and liver lipid peroxidation, along with DNA damage, PCNA and CK-7 expression, and altered gene expression of cytokines.

Oxidative hepatic damage and change in liver architecture with significant decrease in GSH concentration, inhibition of SOD and CAT activity, and increased MDA level have been previously reported in a liver toxicity model of rats [31,32], and a link between change in antioxidant status and liver histopathology owing to liver injury has been described [33]. Additionally, decreased activity of SOD and CAT, reduced GSH concentration, and increased MDA level have been suggested to be responsible for oxidative damage and apoptosis in TAC-induced diabetes mellitus in an animal model [34]. MDA reflects lipid peroxidation and plays a vital role on oxidative damage. These evidences support the notion that histopathological changes with decreased concentration of GSH, reduced activity of SOD and CAT, and increased level of MDA may be due to oxidative hepatic damage in experimental groups. Moreover, DNA damage in our study, as evidenced by TUNEL-positive cells in TAC-treated groups, might attribute to the decrease in antioxidant status and increased lipid peroxidation in the liver. Liver injury due to decreased GSH concentration, reduced SOD and CAT activity, elevated MDA level, and DNA damage has been described in previous studies due to the production of reactive oxygen species [35-37]. This fact suggests that oxidative stress can induce apoptosis in the liver, which in turn can further exacerbate inflammation.

Several factors, such as hypoxia, pathological injury, and cell proliferation via the NOD-like receptor inflammasome pathway, contribute to increased expression of PCNA and CK-7 in the liver [38-41]. Increased expression of CK-7 and PCNA has been reported in liver transplant patients due to recurrence of liver complications, drug toxicityinduced hypoxia, and liver fibrosis [42-44]. Increased expression of PCNA and CK-7 in current findings may imply liver injury associated with dysregulation of antioxidants and lipid peroxidation.

Cytokines IL-10 and IL-13 are considered as antiinflammatory and upregulated in acute liver injury and liver fibrosis to prevent the damage $[23,45,46]$. Song et al. have reported that using sirolimus as an immunosuppressive drug resulted in increased level of IL-10 in liver transplant patients by affecting B cell regulatory cells [47]. Impaired activity of
SOD and MDA level with upregulation of IL-10 and IL-13 expression indicate inflammation and acute liver injury due to production of ROS $[45,48,49]$. These cytokines are also responsible for activation of the suppressor of cytokine signaling (SOCS) genes which can activate other signal transduction pathways, such as the JACK/STAT pathway to promote cell proliferation and apoptosis [25]. A link between augmented expressions of SOCS-1, -2 , and -3 in hepatocytes due to endotoxin-associated inflammation has been reported [50]. Previous studies have also confirmed an increased expression of SOCS-3, IL-10, and TNF $\alpha$ in liver steatosis patients [51]. As suggested in previous studies, upregulation of cytokines in current findings may also indicate an inflammatory response. Our results highlighted an augmented mRNA expression of IL-10, IL-13, SOCS-2, and SOCS-3, which may attribute to proinflammatory reaction mediated by change in antioxidant status and lipid peroxidation.

Taken together, this data implies that even short-term TAC exposure could induce histopathological changes in tandem with changes in serum antioxidant status, liver lipid peroxidation, DNA damage, overexpression of PCNA and CK-7, and an impact on hepatic gene expression of cytokines. Therefore, to minimize rejection-related issues, these factors should be considered in case of prolonged immunosuppressive therapy in order to improve life expectancy of transplant patients. However, further studies with a multifaceted approach should be conducted using combination drugs in a chronic model of TAC exposure on rats, which is a limitation of this study.

\section{Data Availability}

Data supporting this research can be available upon request.

\section{Conflicts of Interest}

The authors declare no conflict of interest.

\section{Acknowledgments}

We are thankful to the Vice Chancellor, University of the Punjab, Lahore, Pakistan, for providing financial support for the accomplishment of this article, and other colleagues for reading the manuscript and critical discussions.

\section{References}

[1] A. A. Araya and Y. Tasnif, Tacrolimus, StatPearls Publishing, 2020.

[2] H. U. Meier-Kriesche, J. D. Schold, T. R. Srinivas, and B. Kaplan, "Lack of improvement in renal allograft survival despite a marked decrease in acute rejection rates over the most recent era," American Journal of Transplantation, vol. 4, no. 3, pp. 378-383, 2004.

[3] Y. C. Lin, C. S. Tsai, I. H. Li et al., "Transplant recipients using tacrolimus had higher utilization of healthcare services than those receiving cyclosporine in Taiwan," Frontiers in Pharmacology, vol. 10, p. 1074, 2019.

[4] T. C. Wong, C. M. Lo, and J. Y. Fung, "Emerging drugs for prevention of $\mathrm{T}$-cell mediated rejection in liver and kidney 
transplantation," Expert Opinion on Emerging Drugs, vol. 22, no. 2, pp. 123-136, 2017.

[5] A. W. Thomson, C. A. Bonham, and A. Zeevi, "Mode of action of tacrolimus (FK506): molecular and cellular mechanisms," Therapeutic Drug Monitoring, vol. 17, no. 6, pp. 584-591, 1995.

[6] Y. Bentata, "Tacrolimus: 20 years of use in adult kidney transplantation. What we should know about its nephrotoxicity," Artificial Organs, vol. 44, pp. 140-152, 2019.

[7] B. Russell, C. Moss, G. George et al., "Associations between immune-suppressive and stimulating drugs and novel COVID-19-a systematic review of current evidence," Ecancermedicalscience, vol. 14, p. 1022, 2020.

[8] C. Zhang, S. Duan, M. Guo et al., "Effects of CYP3A5 polymorphisms on efficacy and safety of tacrolimus therapy in patients with idiopathic membranous nephropathy," Pharmacogenomics and Personalized Medicine, vol. 13, pp. 141-149, 2020.

[9] A. S. Ali, A. S. Almalki, and B. T. Alharthy, "Effect of Kaempferol on tacrolimus-induced nephrotoxicity and calcineurin B1 expression level in animal model," Journal of Experimental Pharmacology, vol. 12, pp. 397-407, 2020.

[10] T. Akhtar, G. Ali, and N. Sheikh, "Immunosuppressantinduced oxidative stress and iron: a paradigm shift from systemic to intrahepatic abnormalities," Oxidative Medicine and Cellular Longevity, vol. 2020, Article ID 8675275, 10 pages, 2020.

[11] A. D. Goralczyk, N. Bari, W. Abu-Ajaj et al., "Calcineurin inhibitor sparing with mycophenolate mofetil in liver transplantion: a systematic review of randomized controlled trials," American Journal of Transplantation, vol. 12, no. 10, pp. 26012607, 2012.

[12] T. Akhtar, N. Sheikh, T. Shan, and R. Ghazanfar, "Tacrolimus induced nephrotoxicity and pulmonary toxicity in Wistar rats," Journal of Biological Regulators and Homeostatic Agents, vol. 31, no. 4, pp. 1061-1066, 2017.

[13] W. C. Tseng, H. C. Lai, C. C. Yeh, H. L. Fan, and Z. F. Wu, "Overdose of tacrolimus as the trigger causing progression of posterior reversible encephalopathy syndrome and subsequent hepatic infarction after liver transplant: a case report," Experimental and Clinical Transplantation, vol. 18, no. 1, pp. 128132, 2020.

[14] A. Nash, M. Samoylova, T. Leuthner et al., "Effects of immunosuppressive medications on mitochondrial function," The Journal of Surgical Research, vol. 249, pp. 50-57, 2020.

[15] N. Undre, I. Hussain, J. Meijer, J. Stanta, G. Swan, and I. Dawson, "Quantitation of tacrolimus in human whole blood samples using the MITRA microsampling device," Therapeutic Drug Monitoring, 2020.

[16] Q. Ling, H. Huang, Y. Han et al., "The tacrolimus-induced glucose homeostasis imbalance in terms of the liver: from bench to bedside," American Journal of Transplantation, vol. 20, pp. 701-713, 2019.

[17] D. L. Jennings, B. Bohn, A. Zuver et al., "Gut microbial diversity, inflammation, and oxidative stress are associated with tacrolimus dosing requirements early after heart transplantation," PLoS One, vol. 15, no. 5, article e0233646, 2020.

[18] H.-l. Zheng, H.-y. Zhang, C.-1. Zhu et al., " $L$-Carnitine protects against tacrolimus-induced renal injury by attenuating programmed cell death via PI3K/AKT/PTEN signaling," Acta Pharmacologica Sinica, vol. 42, no. 1, pp. 77-87, 2021.
[19] Z. Geng, Y. Zhang, S. Wang et al., "Radiomics analysis of susceptibility weighted imaging for hepatocellular carcinoma: exploring the correlation between histopathology and radiomics features," Magnetic Resonance in Medical Sciences, 2020.

[20] M. N. B. Ramli, Y. S. Lim, C. T. Koe et al., "Human pluripotent stem cell-derived organoids as models of liver disease," Gastroenterology, vol. 159, no. 4, pp. 1471-1486.e12, 2020.

[21] E. Tousson, E. Hafez, M. M. Abo Gazia, S. B. Salem, and T. F. Mutar, "Hepatic ameliorative role of vitamin B17 against Ehrlich ascites carcinoma-induced liver toxicity," Environmental Science and Pollution Research International, vol. 27, no. 9, pp. 9236-9246, 2020.

[22] O. Cengiz, M. Baran, E. Balcioglu et al., "Use of selenium to ameliorate doxorubicin induced hepatotoxicity by targeting pro-inflammatory cytokines," Biotechnic \& Histochemistry, vol. 96, no. 1, pp. 67-75, 2021.

[23] Y. Huang, J. Lu, Y. Xu et al., "Xiaochaihu decorction relieves liver fibrosis caused by Schistosoma japonicum infection via the HSP47/TGF- $\beta$ pathway," Parasites \& Vectors, vol. 13, no. 1 , p. 254, 2020.

[24] K. S. Kang, S. Shin, and S. I. Lee, "N-acetylcysteine modulates cyclophosphamide-induced immunosuppression, liver injury, and oxidative stress in miniature pigs," Journal of Animal Science and Technology, vol. 62, no. 3, pp. 348-355, 2020.

[25] W. S. Bin, Q. U. Ain, A. Quraishi, and B. Wahid, "Clinical correlation of liver function tests with suppression of cytokine signaling (SOCS1) gene expression in HCV infected patients: a real-world clinical experience," Journal of Medical Virology, vol. 92, pp. 257-259, 2020.

[26] T. Akhtar and N. Sheikh, "Induction of acute phase in response to tacrolimus induced hepatotoxicity," Punjab University Journal of Zoology, vol. 31, pp. 77-82, 2016.

[27] F. Azam, N. Sheikh, G. Ali, and A. Tayyeb, "Fagonia indica Repairs Hepatic Damage through Expression Regulation of Toll- Like Receptors in a Liver Injury Model," Journal of Immunology Research, vol. 2018, Article ID 7967135, 12 pages, 2018.

[28] S. Lo, J. C. Russell, and A. W. Taylor, "Determination of glycogen in small tissue samples," Journal of Applied Physiology, vol. 28, no. 2, pp. 234-236, 1970.

[29] M. Krishna, "Role of special stains in diagnostic liver pathology," Clinical Liver Disease, vol. 2, Supplement 1, pp. S8-S10, 2013.

[30] N. Fedchenko and J. Reifenrath, "Different approaches for interpretation and reporting of immunohistochemistry analysis results in the bone tissue - a review," Diagnostic Pathology, vol. 9, no. 1, p. 221, 2014.

[31] P. Huang, G. Li, C. Chen et al., "Differential toxicity of Mn2+ and $\mathrm{Mn} 3+$ to rat liver tissues: oxidative damage, membrane fluidity and histopathological changes," Experimental and Toxicologic Pathology, vol. 64, no. 3, pp. 197-203, 2012.

[32] N. Djaber, L. S. Ounaceur, B. N. Moubine et al., "Roundupinduced biochemical and histopathological changes in the liver and kidney of rats: the ameliorative effects of Linum usitatissimum oil," Acta Biochimica Polonica, vol. 67, no. 1, pp. 53-64, 2020.

[33] S. K. Swain, D. U. Chandra, S. Kanhar, and A. K. Sahoo, “Ameliorative effects of Hydrolea zeylanica in streptozotocininduced oxidative stress and metabolic changes in diabetic rats," Journal of Ethnopharmacology, vol. 247, p. 112257, 2020. 
[34] Y. Quan, K. Luo, S. Cui et al., "The therapeutic efficacy of water-soluble coenzyme Q10 in an experimental model of tacrolimus-induced diabetes mellitus," The Korean Journal of Internal Medicine, vol. 35, no. 6, pp. 1443-1456, 2020.

[35] W. A. Q. Hailan, F. M. Abou-Tarboush, K. M. Al-Anazi, A. Ahmad, A. Qasem, and M. A. Farah, "Gemcitabine induced cytotoxicity, DNA damage and hepatic injury in laboratory mice," Drug and Chemical Toxicology, vol. 43, no. 2, pp. 158$164,2020$.

[36] B. Li, W. Li, Y. Tian et al., "Selenium-alleviated hepatocyte necrosis and DNA damage in cyclophosphamide-treated geese by mitigating oxidative stress," Biological Trace Element Research, vol. 193, no. 2, pp. 508-516, 2020.

[37] S. Özdemir, S. Kucukler, S. Çomaklı, and F. M. Kandemir, "The protective effect of morin against ifosfamide-induced acute liver injury in rats associated with the inhibition of DNA damage and apoptosis," Drug and Chemical Toxicology, pp. 1-10, 2020.

[38] H. El Baz, Z. Demerdash, M. Kamel et al., "Induction of hepatic regeneration in an experimental model using hepatocyte-differentiated mesenchymal stem cells," Cellular Reprogramming, vol. 22, no. 3, pp. 134-146, 2020.

[39] F. S. Wang, M. L. Yu, W. Z. Li, K. Hong, C. B. Xu, and G. H. Wang, "Intestinal tract and parenteral multi-organ sequential pathological injury caused by necrotizing enterocolitis," $B M C$ Pediatrics, vol. 20, no. 1, p. 418, 2020.

[40] L. Shi, S. Zhang, Z. Huang et al., "Baicalin promotes liver regeneration after acetaminophen-induced liver injury by inducing NLRP3 inflammasome activation," Free Radical Biology \& Medicine, vol. 160, pp. 163-177, 2020.

[41] M. Nakao, N. Kono, S. Adachi et al., "Abnormal increase in the expression level of proliferating cell nuclear antigen (PCNA) in the liver and hepatic injury in rats with dietary cobalamin deficiency," Journal of Nutritional Science and Vitaminology (Tokyo), vol. 52, no. 3, pp. 168-173, 2006.

[42] N. Sansotta, R. Agazzi, A. Sonzogni, M. Colledan, A. Ferrari, and L. D'Antiga, "Subclinical biliary strictures as a cause of long-term allograft dysfunction in children who underwent liver transplantation," American Journal of Transplantation, vol. 21, no. 1, pp. 391-399, 2021.

[43] G. Schmit, J. Lelotte, J. Vanhaebost, Y. Horsmans, B. M. Van, and P. Baldin, "The liver in COVID-19-related death: protagonist or innocent bystander?," Pathobiology, vol. 88, pp. 1-7, 2020.

[44] M. Mercado-Gómez, F. Lopitz-Otsoa, M. Azkargorta et al., "Multi-omics integration highlights the role of ubiquitination in CCl(4)-induced liver fibrosis," International Journal of Molecular Sciences, vol. 21, article 9043, 2020.

[45] X. Li, H. Li, D. Cai et al., "Chronic oral exposure to cadmium causes liver inflammation by NLRP3 inflammasome activation in pubertal mice," Food and Chemical Toxicology, vol. 148, article 111944, 2020.

[46] Q. Wang, Y. Zhao, and B. Zang, "Anti-inflammation and antiapoptosis effects of growth arrest-specific protein 6 in acute liver injury induced by LPS/D-GalN in mice," Acta Cirúrgica Brasileira, vol. 35, no. 2, article e202000204, 2020.

[47] J. Song, G. Du, W. Chen et al., "The advantage of sirolimus in amplifying regulatory $\mathrm{B}$ cells and regulatory $\mathrm{T}$ cells in liver transplant patients," European Journal of Pharmacology, vol. 869, p. 172872, 2020.
[48] Y. Zhang, Y. Biao, X. Chu et al., "Protective effect of Chushizi (Fructus Broussonetiae) on acetaminophen-induced rat hepatitis by inhibiting the toll-like receptor $3 / \mathrm{c}$-Jun $\mathrm{N}$-terminal kinase/c-Jun/c-fos/Janus protein tyrosine kinase/activators of transcription 3 pathway," Journal of Traditional Chinese Medicine, vol. 40, no. 6, pp. 965-973, 2020.

[49] Y. Li, Y. Chen, X. Huang et al., "Tanshinol A ameliorates triton-1339W-induced hyperlipidemia and liver injury in C57BL/6J mice by regulating mRNA expression of lipemicoxidative injury genes," Lipids, vol. 55, no. 2, pp. 127-140, 2020.

[50] X. Jiang, M. He, J. Bai, C. B. Chan, and A. O. L. Wong, "Signal transduction for $\mathrm{TNF} \alpha$-induced type II SOCS expression and its functional implication in growth hormone resistance in carp hepatocytes," Frontiers in Endocrinology, vol. 11, p. 20, 2020.

[51] M. Farooq, M. Rauf, F. Tahir, and S. Manzoor, "A comparative analysis of interferons and direct-acting antivirals on the expression of genes involved in hepatitis C pathogenesis," Journal of Medical Virology, 2020. 